\title{
Article \\ Solar-Powered Active Road Studs and Highway Infrastructure: Effect on Vehicle Speeds
}

\author{
Richard Llewellyn*D, Jonathan Cowie and Grigorios Fountas \\ Transport Research Institute, Edinburgh Napier University, Edinburgh EH10 5DT, UK; j.cowie@napier.ac.uk (J.C.); \\ g.fountas@napier.ac.uk (G.F.) \\ * Correspondence: r.llewellyn@napier.ac.uk; Tel.: +44-(0)131-455-3755
}

\begin{abstract}
Vehicle speeds have a direct relationship with the severity of road crashes and may influence their probability of occurrence. Solar-powered active road studs have been shown to have a positive effect on driver confidence, but their impact on vehicle speed in conjunction with other road features is little understood. This study aims to address this gap in knowledge through a case study of a $20 \mathrm{~km}$ section of a strategic major road featuring a variety of highway infrastructure features. Before-and-after surveys were undertaken at 21 locations along the route using manual radar speed measurement. Analysis of nearly 10,000 speed measurements showed no statistically significant change in mean speeds following the implementation of the road studs. Linear regression models are proposed for two different posted speed limits, associating road features with expected vehicle speed. The models suggest that vehicle speeds are chiefly influenced by merges, curves, gradients, and ambient light conditions. The findings of this study should provide confidence that active road studs may be implemented without a negative impact on speed-related safety. The work also provides further expansion of the evidence base describing the effect of highway infrastructure features on vehicle speeds.
\end{abstract}

Citation: Llewellyn, R.; Cowie, J.; Fountas, G. Solar-Powered Active Road Studs and Highway Infrastructure: Effect on Vehicle Speeds. Energies 2021, 14, 7209 . https://doi.org/10.3390/en14217209

Academic Editors: Marek Guzek, Rafał Jurecki and Wojciech Wach

Received: 17 October 2021

Accepted: 30 October 2021

Published: 2 November 2021

Publisher's Note: MDPI stays neutral with regard to jurisdictional claims in published maps and institutional affiliations.

Keywords: active road studs; highway infrastructure; vehicle speeds; road safety; road features

\section{Introduction}

Road traffic crashes are the eighth leading cause of death globally with an estimated 1.35 million killed and 50 million injured each year [1]. Speed management has a long association with road safety and is enshrined within contemporary international road safety strategies such as the safe systems approach [2,3]. Such strategies are founded upon the basis that the consequences of crashes at higher speeds are a simple matter of physics: the greater the change in velocity, the greater the energy dissipation and, subsequently, the higher the severity of injury [4]. On this basis, understanding the relationships between drivers, vehicles, road infrastructure, and speed continues to be an important goal of road safety research.

Early case-control studies in speed research suggested that the greater the differential in the speed of a vehicle from the average of all the traffic, the higher the risk of a crash $[5,6]$. Self-reporting studies have also found that drivers found to be travelling faster are more likely to have a history of crashes [7]. More recent research has tended to look at the road level (including segments, sections, intersections, and corridors), rather than individual driver level, not least because of the difficulties of categorically associating speed as a causation factor in individual crashes [8]. The question then becomes one of how the frequency and severity of the crashes vary with mean speed, to which the answer has been extensively explored; before-and-after studies of measures, such as changes in the posted speed limit, traffic calming interventions, or increased enforcement have resulted in linear, power, and asymptotic relationships associating higher mean speeds with increased crash rates [9-14]. Therefore, from the point of view of the road designer, road features that result in unintended increases in mean speed are unlikely to be desirable. 
In several countries across the world, reflective road studs are used as a measure to assist drivers in low light by highlighting road features, such as lanes, carriageway edges, curvature, and junctions. They rely on the reflection of the vehicle's headlight beam back to the driver to provide a preview of oncoming features. However, such a system is limited in range by the power of the vehicle headlights and can be further affected by weather and the physical condition of the studs themselves. Active Road Studs (also known as Internally Illuminated Raised Pavement Markers) are a recent development which seeks to address such issues. The studs feature high-powered LEDs which significantly increase the preview time of the road ahead and have been suggested as being of assistance to drivers in several road scenarios $[15,16]$. They have also been shown to have a positive impact on driver confidence [17]. However, if increased confidence were to result in a corresponding increase in speed, this could potentially compromise any road safety gains made. On this basis, the effect of active road studs on vehicle speeds in the context of other road features is of particular interest.

The relationship between active road studs and speed has been the subject of several simulator studies exploring the behaviour of drivers with and without their implementation. One such study investigated thirty-six participants split evenly across three age groups over a $37 \mathrm{~km}$ generic, rural, single carriageway route, with matching sections of no studs, passive (i.e., traditional reflective) studs, and active studs [18]. The simulation showed statistically significant increases in mean speed along the route between the nostud and the passive- or active-stud sections. However, no statistically significant difference was found between passive and active road studs. Looking at corners alone, the same results were found for right-hand curves. For left-hand curves, an increase was found in mean speed for the youngest and oldest driver groups. Drivers were also found to brake more strongly for both studded conditions on corners, but there was no significant difference in braking between active and passive studs.

A later simulator study compared the speed of drivers on a route with no studs, active studs on curves, and full road lighting on curves [19]. In this case, the studs were activated by an approaching vehicle and switched off once the vehicle had passed. The distance between studs was also varied; larger distances between studs were applied on the approach, with smaller distances on the curve itself. Twenty participants drove the route, comprising sixteen straight and sixteen curved sections. On the straight sections, higher mean speeds were recorded with both the stud and the lighting treatment when compared with the unlit route; however, no significant difference was found between the mean speeds of the studded and lit conditions. Overall, faster speeds were found on the approach to curves than within them. Noting that this study was based on right-hand driving, in right-hand curves no differences between the three speeds were found. For left-hand curves, the speed on the approaches was higher with the lighting than with the studs or no treatment.

Regarding the speed effects of active road studs in real-world applications, a beforeand-after video study of an undefined length of road was undertaken between two bends in Victoria, Australia $[20,21]$. The reductions in mean speed before and after installation in each direction were found to be $1.2 \mathrm{~km} / \mathrm{h}(0.7 \mathrm{mph})$ and $3.1 \mathrm{~km} / \mathrm{h}(1.9 \mathrm{mph})$, respectively. However, the change was only statistically significant in the latter case, and the methods of control for other confounding factors were not detailed. A review of the literature, practitioner feedback, and manufacturers undertaken in the United States included speed effects on highway junctions and links in its scope [22]. Whilst the reporting of reduced speed was suggested as a possible outcome in the review, it notes that the data were limited and could not be considered conclusive.

The research to date on the relationship between active road studs and speed is limited to simulator-based studies or very small field installations. Furthermore, the focus of the existing work has been on plain tangent and curve sections and has not covered potential mean-speed changes at other road features, such as junction approaches, merges, and dual carriageway sections. The present work attempts to address this gap in knowledge. On 
this basis, the aim of this research was to measure the choice of speed by drivers, using real-world rural junctions and links and to determine whether changes in the speed of vehicles may be associated with the installation of active road studs when compared to other road features. Building on the findings of previous studies, the stated hypothesis is that the implementation of active road studs results in no change in speed when compared to their traditional reflective equivalent and that other road features are associated with differences in mean speed. The objectives were to:

- quantify the speed choice of drivers on typical rural-road infrastructure;

- survey and record factors in the road environment that may affect speed choice, including active road studs;

- identify and assess the effect of such factors against actual vehicle speeds; and

- identify the response to such factors over a longer time frame.

The work described here forms part of a larger study investigating the effects of active road studs on driver behaviour, such as lane discipline, gap acceptance, and driver confidence. The focus in this element is the effect of active road studs on vehicle speeds. Section 2 describes the materials and methods adopted, including the background to the case study chosen, the procedure used for obtaining the speed and infrastructure data, and the statistical methods used for the analysis. Section 3 states the results of the route and individual site surveys and the development of the linear regression model. The findings are discussed in the context of the existing literature in Section 4, with conclusions and implications for practitioners identified in Section 5.

\section{Materials and Methods}

\subsection{Case Study Background}

The A1 trunk road (a route of national strategic importance) runs between Edinburgh and London in the UK. The road is constructed to dual carriageway or motorway standard for most of its length, but the section straddling the border between Scotland and England is more mixed in its composition. It also carries a lower volume of traffic than other parts of the route. Although complying with modern alignment standards due to extensive upgrading in the latter half of the 20th century, it mainly consists of single carriageway, with a posted speed limit of $60 \mathrm{mph}(97 \mathrm{~km} / \mathrm{h})$. Short sections of $2+1$ carriageway and higher speed $70 \mathrm{mph}(113 \mathrm{~km} / \mathrm{h})$ dual carriageway are provided at intervals to provide overtaking opportunities. The speed limits for heavy goods vehicles (HGVs) are $20 \mathrm{mph}$ lower than the posted limit at $40 \mathrm{mph}(64 \mathrm{~km} / \mathrm{h})$ and $50 \mathrm{mph}(80 \mathrm{~km} / \mathrm{h})$ for the single and dual carriageway sections, respectively. The route is particularly rural in nature, carrying national strategic traffic along with linking local towns and villages. During the hours of darkness, there is very little ambient light due to its location away from major population centres. Street lighting is provided at certain points, but the route is predominantly unlit.

The case study for this research is a $20 \mathrm{~km}$ section of the A1 in Scotland immediately north of its border with England. The route here has a modest crash rate relative to other Scottish trunk roads; this has been associated with fixed-enforcement-camera treatment [23]. Nevertheless, local communities have continued to raise safety concerns, prompting a review by the national roads authority. The review found that the legibility of the route during hours of darkness, particularly around junctions, could be problematic. An improvement scheme was proposed [24] comprising the installation of 4200 solar-powered active road studs to highlight the approaches to nine junctions and two intermediate carriageway sections. The active road studs were effectively a like-for-like replacement of the reflective road studs which were already in situ. In accordance with the UK traffic sign regulations, white, red, amber, and green studs were used to indicate the centreline, nearside and offside edge lines, and the merge/diverge sections, respectively. Examples of typical active road stud installations implemented as part of the scheme are shown in Figure 1. 


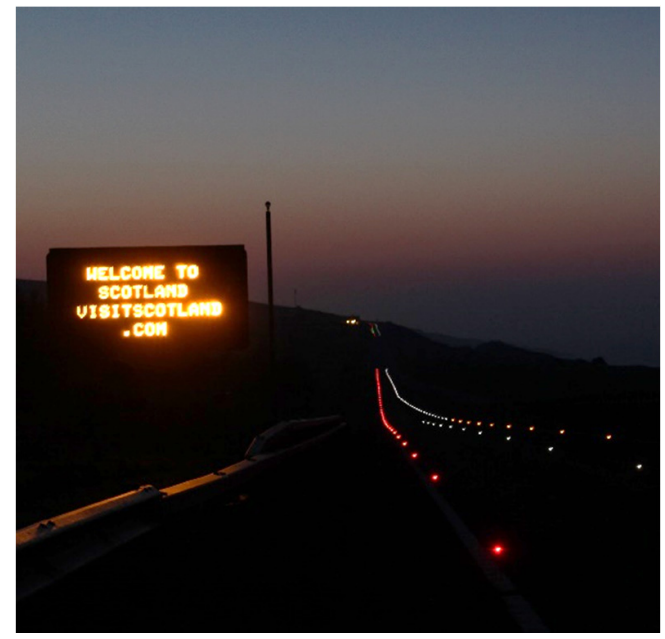

(a)



(c)

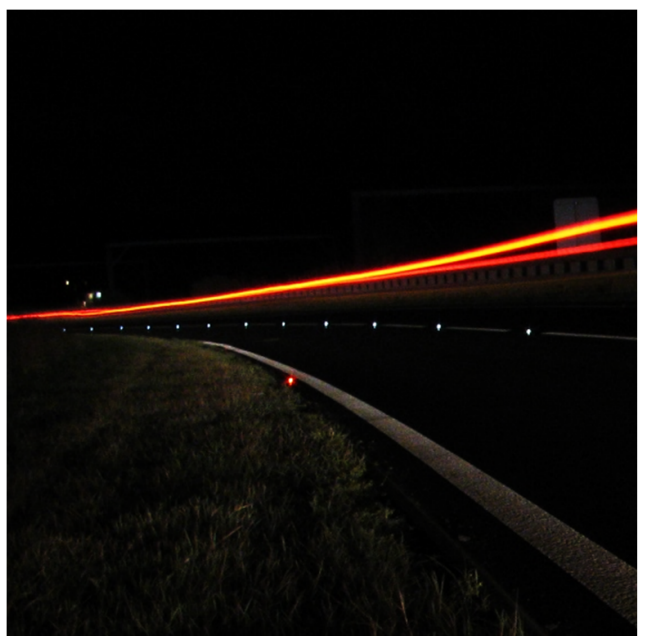

(b)

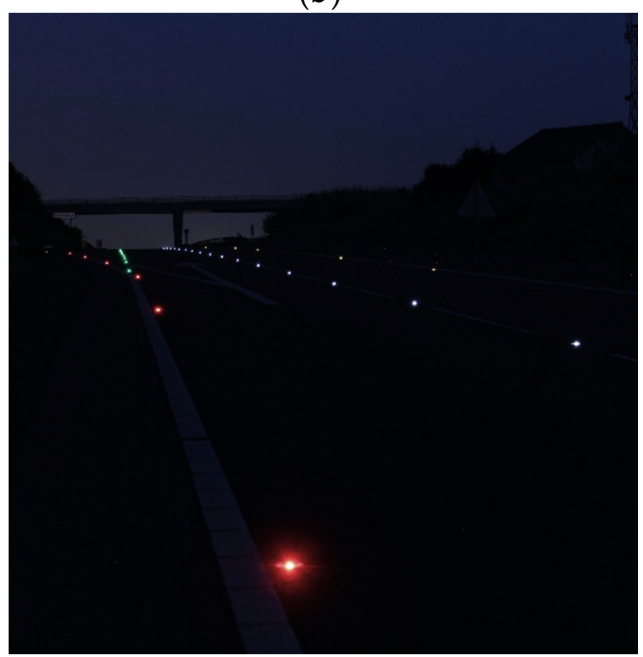

(d)

Figure 1. Example active stud installations: (a) dual to single carriageway merge; (b) single carriageway curve; (c) single carriageway junction; (d) dual carriageway junction.

\subsection{Methodological Considerations}

Two methods were considered for the measurement of speeds on the treated section of the route. The first option was the use of automatic traffic counters. Such counters have the benefit of being able to record a large amount of data over a continuous period, resulting in a large sample size and coverage of a range of conditions. With careful installation, they can be installed relatively inconspicuously to avoid any potential influence on the results. However, as an observer is not usually continuously present, confounding factors, such as incidents and inclement weather conditions, can mean collected speed data may not be fully representative. The accuracy of the automatic traffic counters can also be affected by irregular vehicle trajectories, detector spacing, scanning time, and multiple vehicles in the detection zone $[25,26]$. The traffic counters also record the speeds of all vehicles passing, irrespective of flow density. As a result, individual recorded speeds may be affected due to the presence of other vehicles and may not reflect a true speed choice by the drivers.

The alternative method considered for measuring speeds was a manual radar survey. Such surveys are labour-intensive and are more limited in the choice of location due to the need for the observer to remain inconspicuous whilst not compromising the safety of the survey staff or other road users. They can also be prone to human error or bias, particularly where the observer is inexperienced. However, manual speed surveys allow for a truer representation of free mean speeds to be recorded as the observer can exercise judgement regarding whether speeds are likely to be by choice; for example, this can be achieved 
by recording speeds only where a certain headway between vehicles is exceeded and by the monitoring of other factors, such as the illumination of brake lights. Other benefits of the continuous presence of an observer include the monitoring of weather conditions and the accounting for any unusual incidents during the survey period. On this basis and in the interests of potentially greater precision, the manual radar survey was selected as the preferred method for this work.

\subsection{Manual Radar Survey Procedure}

Manual survey locations were established on each approach to the treated junctions and mid-link on the curve and merge sections. A pre-survey reconnaissance visit was undertaken to determine the exact location of each site in order to consider the health and safety of the enumerator, the covertness of the survey, and the potential accuracy of the recording. Specific concerns at each location included the angle of the radar beam, the depth of field, the field of view to the traffic flow, and the presence of objects which may have resulted in unwanted radar reflection. In total, 21 sites were established. Prior to each survey being undertaken, weather forecasts and traffic-incident information were checked and rescheduled if conditions were considered sub-optimal. This ensured that weather and unexpected traffic conditions were controlled for all surveys being undertaken during 'neutral' conditions, i.e., good visibility, no precipitation, light or no winds, generally dry road surfaces, and normal traffic flows. A typical radar survey arrangement is shown in Figure 2.

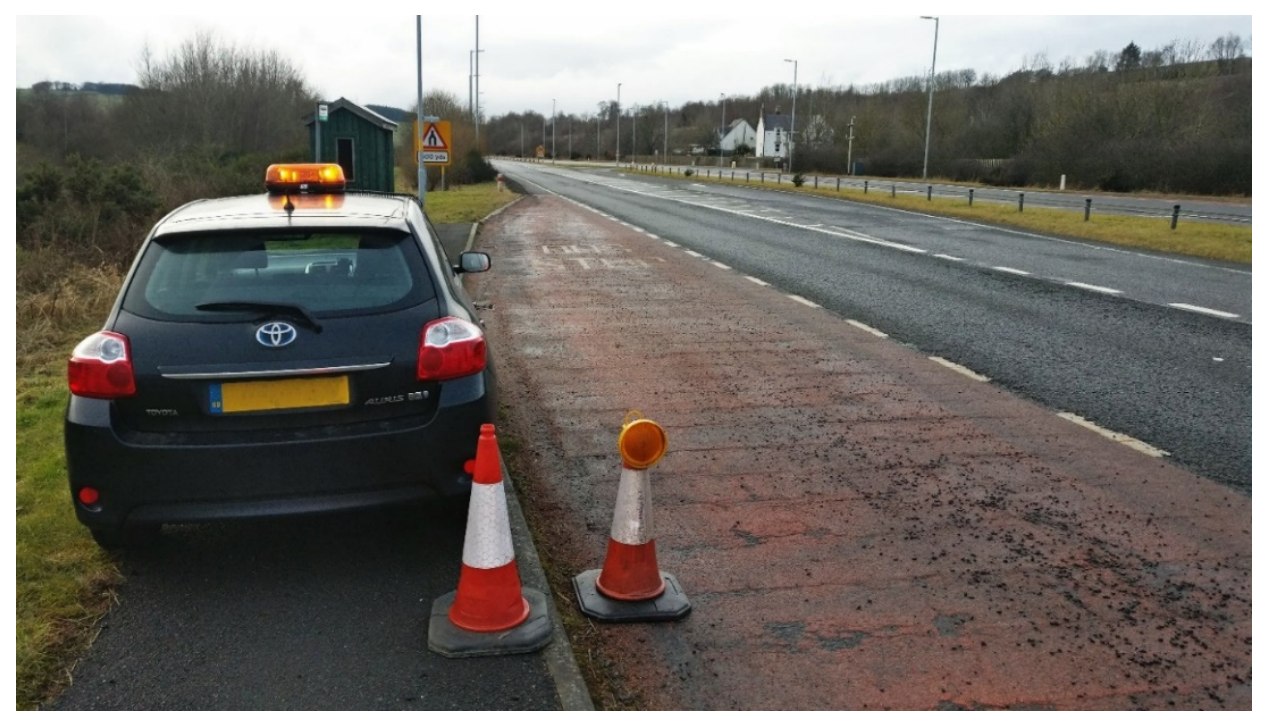

Figure 2. Typical radar speed survey arrangement.

To provide an adequate sample size, the surveys were carried out for a minimum of one hour at each location, or longer if a minimum threshold of sixty vehicles had not been reached. Only vehicles subject to free flow conditions were recorded, defined as where a headway of greater than three seconds existed, as used in other similar studies (e.g., [7]. Wherever practicable, every vehicle travelling in such conditions was recorded. The speeds were recorded directly into a spreadsheet during the survey itself, with cosine corrections applied if local factors required a larger angle of measurement. Each site was surveyed once during the hours of daylight and once during the hours of darkness. The exercise was repeated three times over a 30-month period: before installation of the active road studs, six months after installation, and two years after installation. The surveys were undertaken in November or February to ensure that sunset times and ambient lighting conditions were controlled to be as similar as possible. 


\subsection{Additional Data Sources}

To investigate other road factors that may influence speed, a combination of Ordnance Survey (UK national mapping agency) vector data, and visual observation of the infrastructure was used. The mapping data was used to derive the vertical and horizontal alignment of the route along with the carriageway widths at each speed-survey location. The gradients on the approach to the survey sites were derived from the vertical alignment profile and presented as a percentage; uphill gradients were recorded as positive and downhill gradients as negative, respectively. Curvature values were taken initially as an absolute centreline radius in metres; these were subsequently recoded into three binary variables corresponding with the desirable minimum, one-step, and two-step relaxation design values from the UK highway design manual [27]. Any radii exceeding $2880 \mathrm{~m}$ were considered tangent sections. The carriageway widths were measured at either end of the zone covered by the radar gun; these values were then averaged and divided by two to provide an effective carriageway half-width for the survey location.

Visual inspection at each survey site provided the posted speed limit (PSL), the presence of street lighting, the presence of $2+1$ carriageway configuration, the locations of junctions or merges, and other features which may affect speed choice. Binary variables were created to represent each feature accordingly. Two further variables were created with respect to the presence of enforcement cameras; one represented the distance since the last camera with the direction of flow, the other the distance since the last camera passed facing either direction. A variable was also coded representing the length of the active road stud installation on the approach to the survey site. Each speed case recorded during the surveys was appended with the previously described variables corresponding to the survey site in question; binary variables were also included for whether the case had been recorded during daylight or darkness and whether it was before or after the implementation of the active road studs.

\subsection{Statistical Analysis}

Quantitative statistical analysis of the speed data was undertaken using the Statistical Package for the Social Sciences (SPSS) v26 (IBM). For the each of the datasets, from before, after, and two years after, descriptive statistics were produced. Z-scores were calculated and used to check for outlying cases of more than three standard deviations from the mean. Levene's test was used to test for equality of variance, and differences in mean were tested for using Welch's $t$-test. The null hypothesis was examined using a two-tailed test with a level of confidence $(\alpha)$ of 0.05 .

At an infrastructure level, descriptive statistics were produced for the 15 variables of interest. Pearson's correlation coefficient was used to assess the association between road-environment factors and speed. Checks were made on the speed-data variables prior to the calculation of the correlation coefficients to determine the suitability of each variable for testing. All variables under test were at the interval or nominal level. Values of between 0.5 and 1 were taken as a high correlation, 0.3 to 0.49 as medium, and 0.1 to 0.29 as small.

Linear regression models were created for the dependent variable of speed and the independent variables of road and environmental features. For model estimation, the Ordinary Least Squares (OLS) approach was used [28]. Two models were created, one for sections of road with a $60 \mathrm{mph}$ posted speed limit, the other for the remaining sections with a $70 \mathrm{mph}$ limit. The stepwise regression function in SPSS was used to create the models. Prior to the process commencing, checks for normality and tests of collinearity were used from the output of the correlation testing previously described. No variable was excluded from the initial list of independent variables. Exclusion of variables was undertaken on a stepwise basis, with $p$-values of 0.05 used for entry and 0.10 used for exclusion. 


\section{Results}

\subsection{Descriptive Statistics}

A sample size of 9135 speed cases was achieved across the survey periods of before, after, and two years after, with similar proportions recorded under each scenario. The recordings were found to approximate a normal distribution with no significant skewness or kurtosis by visual check. There was some evidence to suggest that the distributions could be slightly bimodal, which is likely to be due to the different speed limits between cars and heavy goods vehicles. However, as individual vehicle-type data had not been collected during the speed surveys, it was not possible to refine the data any further. On this basis, the datasets were retained for further analysis unchanged. The descriptive statistics for the total number of cases under the three scenarios are shown in Table 1.

Table 1. Descriptive statistics by scenario and light conditions for route.

\begin{tabular}{ccccccc}
\hline Scenario & $\boldsymbol{n}$ & $\begin{array}{c}\text { Min Speed } \\
\mathbf{( m p h )}\end{array}$ & $\begin{array}{c}\text { Max Speed } \\
\mathbf{( m p h )}\end{array}$ & \multicolumn{2}{c}{$\begin{array}{c}\text { Mean Speed (mph) } \\
\text { Value }\end{array}$} & $\begin{array}{c}\text { Standard Deviation } \\
\text { Standard Error }\end{array}$ \\
\hline Before Treatment & 3297 & 27 & 97 & 56.89 & 0.155 & 8.902 \\
Light & 1779 & 29 & 90 & 56.51 & 0.207 & 8.748 \\
Dark & 1518 & 27 & 97 & 57.35 & 0.233 & 9.062 \\
After Treatment & 3032 & 28 & 104 & 56.53 & 0.153 & 8.405 \\
Light & 1597 & 28 & 95 & 56.01 & 0.201 & 8.035 \\
Dark & 1435 & 34 & 104 & 57.11 & 0.231 & 8.764 \\
Two Years After & 2856 & 35 & 92 & 56.01 & 0.150 & 7.020 \\
Light & 1577 & 35 & 86 & 55.76 & 0.194 & 7.687 \\
Dark & 1279 & 35 & 92 & 56.33 & 0.235 & 8.404 \\
\hline
\end{tabular}

\subsection{Change in Route Mean and Mean Excess Speed}

The significance testing for the changes in the global mean speed along the route is shown in Table 2 for the $60 \mathrm{mph}$ and $70 \mathrm{mph}$ posted speed limits, respectively. The F and $t$ values for Levene's test for equality of variance and Welch's test for equality of means are shown, respectively, along with the associated probability $(p)$ values and the degrees of freedom (df). For the $60 \mathrm{mph}$ posted speed limit sections, the changes in the calculated overall mean speed $(\Delta \overline{\mathrm{v}})$ after the implementation of the active road studs were negligible. During the hours of darkness in both scenarios, the mean speeds were reduced compared with the situation before installation. In the hours of daylight, a negligible reduction was recorded six months after installation, followed by a small increase after two years. No scenario was recorded with a significance level less than 0.05; therefore, in terms of the global mean speeds of the route, the null hypothesis cannot be rejected for the $60 \mathrm{mph}$ posted speed limit sites.

For the speed distributions at the $70 \mathrm{mph}$ posted speed limit sites, a reduction in mean speed of $1 \mathrm{mph}$ overall was apparent six months after the treatment, or $1.5 \mathrm{mph}$ during the hours of darkness. This reduced in magnitude slightly after two years, but a decrease was still apparent. In the former case, the results were recorded at a significance level of less than 0.05 , and the null hypothesis may be rejected. Furthermore, a statistically significant change in variance could be observed during the six months after the treatment in all lighting conditions, although this was no longer the case two years after implementation.

The significance testing for changes in mean excess speeds (i.e., speeds greater than the posted limit) is shown in Table 3 for the $60 \mathrm{mph}$ and $70 \mathrm{mph}$ posted speed limit sections, respectively. The changes in the mean excess speed after the implementation of the active road studs were generally negligible. The differences in any change in mean excess speed between light and dark conditions were found to be broadly similar in both magnitude and direction in each scenario. Only the change in mean excess speed in the $60 \mathrm{mph}$ scenario after two years approached significance; for the other scenarios, the null hypothesis cannot be rejected. 
Table 2. Change in mean speed by posted speed limit.

\begin{tabular}{|c|c|c|c|c|c|c|c|}
\hline \multirow[t]{2}{*}{ PSL } & \multirow[t]{2}{*}{ Scenario } & \multicolumn{2}{|c|}{$\begin{array}{l}\text { Equality of } \\
\text { Variance }\end{array}$} & \multicolumn{4}{|c|}{ Equality of Means } \\
\hline & & $\mathbf{F}$ & $p$ & $\mathbf{t}$ & df & $p$ & $\begin{array}{c}\Delta \overline{\mathbf{v}} \\
(\mathbf{m p h})\end{array}$ \\
\hline \multirow[t]{6}{*}{$60 \mathrm{mph}$} & After Treatment & 0.252 & 0.616 & 0.543 & 4139 & 0.587 & -0.117 \\
\hline & Light & 4.669 & $0.031^{\mathrm{a}}$ & 0.247 & 1894 & 0.349 & -0.071 \\
\hline & Dark & 2.183 & 0.140 & 0.454 & 1880 & 0.650 & -0.149 \\
\hline & Two Years After & 9.281 & $0.002^{\mathrm{a}}$ & 0.353 & 4301 & 0.724 & -0.072 \\
\hline & Light & 13.394 & $0.000^{\mathrm{a}}$ & -0.615 & 2302 & 0.539 & 0.167 \\
\hline & Dark & 0.307 & 0.579 & 1.033 & 1965 & 0.302 & -0.318 \\
\hline \multirow[t]{6}{*}{$70 \mathrm{mph}$} & After Treatment & 10.289 & $0.001^{\mathrm{a}}$ & 2.808 & 2137 & $0.005^{\mathrm{a}}$ & -1.094 \\
\hline & Light & 6.656 & $0.010^{\mathrm{a}}$ & 1.628 & 1130 & 0.104 & -0.839 \\
\hline & Dark & 4.639 & $0.031^{\mathrm{a}}$ & 2.576 & 971 & $0.010^{\mathrm{a}}$ & -1.527 \\
\hline & Two Years After & 1.333 & 0.248 & 1.581 & 1634 & 0.114 & -0.695 \\
\hline & Light & 1.845 & 0.175 & 0.622 & 892 & 0.534 & -0.351 \\
\hline & Dark & 0.114 & 0.736 & 1.684 & 742 & 0.093 & -1.163 \\
\hline
\end{tabular}

${ }^{a}$ Denotes significant result $(p<0.05)$.

Table 3. Change in mean excess speed by posted speed limit.

\begin{tabular}{cccccc}
\hline PSL & Scenario & & \multicolumn{2}{c}{ Equality of Means } & \\
& & $\mathbf{t}$ & $\mathbf{d f}$ & $\boldsymbol{p}$ & $\begin{array}{c}\Delta \overline{\mathbf{v}} \\
(\mathbf{m p h})\end{array}$ \\
\hline \multirow{2}{*}{$60 \mathrm{mph}$} & & & & -0.228 \\
& After Treatment & 0.618 & 481 & 0.536 & -0.583 \\
& Light & 1.396 & 219 & 0.164 & -0.033 \\
& Dark & 0.059 & 261 & 0.953 & -0.650 \\
& Two Years After & 1.983 & 474 & $0.048^{\mathrm{a}}$ & -0.619 \\
& Light & 1.523 & 234 & 0.132 & -0.062 \\
\hline $70 \mathrm{mph}$ & Dark & 1.184 & 239 & 0.237 & -0.938 \\
& After Treatment & 1.700 & 314 & 0.090 & -0.708 \\
& Light & 1.048 & 124 & 0.297 & -1.357 \\
& Dark & 1.604 & 181 & 0.111 & -0.396 \\
& Two Years After & 0.713 & 267 & 0.476 & -0.624 \\
& Light & 1.038 & 140 & 0.301 & \\
& Dark & 0.220 & 132 & 0.826 & -0.200 \\
\hline
\end{tabular}

a Denotes significant result $(p<0.05)$.

\subsection{Change in Mean Speed by Site}

Changes in the local mean speed on an individual site basis along the route were assessed; the results of the analysis are shown in Table 4. The results suggest that the null hypothesis cannot be rejected at most sites. Five sites showed statistically significant changes in mean speeds immediately after treatment, increasing to nine sites after two years. The changes were mixed in direction and magnitude. Immediately after the stud installation, a decrease in mean speeds was seen at four sites and an increase at one. Two years after the installations, six sites had decreased in mean speed and three had increased. The largest statistically significant decrease in mean speed was $3.5 \mathrm{mph}$ and the largest increase was $4.6 \mathrm{mph}$. 
Table 4. Change in local mean speed by site.

\begin{tabular}{|c|c|c|c|c|c|c|c|c|}
\hline \multirow[b]{2}{*}{$\begin{array}{c}\text { Site } \\
\text { Reference }\end{array}$} & \multicolumn{4}{|c|}{ Six Months after Treatment } & \multicolumn{4}{|c|}{ Two Years after Treatment } \\
\hline & $\mathbf{t}$ & df & $p$ & $\begin{array}{c}\Delta \overline{\mathbf{v}} \\
(\mathrm{mph})\end{array}$ & $\mathbf{t}$ & df & $p$ & $\begin{array}{c}\Delta \overline{\mathbf{v}} \\
(\mathrm{mph})\end{array}$ \\
\hline 1 & -3.143 & 245 & $0.002^{\mathrm{a}}$ & 2.309 & -6.901 & 310 & $0.000^{\mathrm{a}}$ & 4.633 \\
\hline 2 & 1.022 & 193 & 0.308 & -0.837 & -1.400 & 218 & 0.163 & 0.981 \\
\hline 3 & 2.106 & 223 & $0.036^{\mathrm{a}}$ & -1.503 & 1.551 & 271 & 0.122 & -0.992 \\
\hline 4 & -0.277 & 233 & 0.782 & 0.253 & -0.925 & 298 & 0.356 & 0.718 \\
\hline 5 & 4.487 & 465 & $0.000^{\mathrm{a}}$ & -3.496 & 2.033 & 297 & $0.043^{\mathrm{a}}$ & -1.917 \\
\hline 6 & 2.086 & 399 & $0.038^{a}$ & -2.105 & 1.399 & 336 & 0.163 & -1.514 \\
\hline 7 & -1.111 & 332 & 0.267 & 1.069 & -0.696 & 281 & 0.487 & 0.734 \\
\hline 8 & -0.257 & 255 & 0.798 & 0.210 & -0.570 & 280 & 0.569 & 0.448 \\
\hline 9 & 0.658 & 210 & 0.511 & -0.561 & 2.357 & 216 & $0.019^{a}$ & -1.939 \\
\hline 10 & -0.232 & 196 & 0.817 & 0.225 & 1.018 & 230 & 0.310 & -0.909 \\
\hline 11 & 0.372 & 214 & 0.710 & -0.361 & 3.894 & 210 & $0.000^{\mathrm{a}}$ & -3.441 \\
\hline 12 & -1.838 & 231 & 0.067 & 1.610 & -3.000 & 231 & $0.003^{\mathrm{a}}$ & 2.552 \\
\hline 13 & -1.547 & 237 & 0.123 & 1.340 & -5.322 & 209 & $0.000^{\mathrm{a}}$ & 3.975 \\
\hline 14 & -1.556 & 273 & 0.121 & 1.467 & -1.261 & 232 & 0.209 & 1.207 \\
\hline 15 & 0.324 & 232 & 0.746 & -0.251 & 0.175 & 217 & 0.861 & -0.128 \\
\hline 16 & 2.034 & 285 & $0.043^{\mathrm{a}}$ & -1.493 & 3.626 & 308 & $0.000^{\mathrm{a}}$ & -2.711 \\
\hline 17 & 1.804 & 279 & 0.072 & -1.165 & 4.480 & 277 & $0.000^{\mathrm{a}}$ & -2.611 \\
\hline 18 & 0.177 & 258 & 0.859 & -0.132 & 2.066 & 257 & $0.040^{\mathrm{a}}$ & -1.679 \\
\hline 19 & -0.986 & 261 & 0.325 & 0.695 & -1.718 & 247 & 0.087 & 1.121 \\
\hline 20 & 0.148 & 444 & 0.882 & -0.119 & 0.128 & 315 & 0.898 & -0.115 \\
\hline 21 & -0.426 & 469 & 0.670 & 0.323 & 0.026 & 372 & 0.979 & -0.022 \\
\hline
\end{tabular}

\subsection{Infrastructure Survey}

The results of the infrastructure survey of the 21 speed-survey sites are shown in Table 5. The table shows a reasonable mix of physical characteristics across the survey sites. During the initial analysis runs, the results from sites 3 and 4 were found to be inconsistent with the other sites. From a legal perspective, these two sites are technically $70 \mathrm{mph}$ dual carriageways. However, whilst the road is physically divided by a central reserve, only single lanes exist in either direction due to pavement hatching markings. The site is located at the transition between the true single carriageway and the dual carriageway sections. Upon inspection, the speeds recorded at this site appeared to be closer to the speeds commensurate with a single carriageway. On this basis, for the purposes of subsequent analysis, the site was recategorized as a $60 \mathrm{mph}$ single carriageway, which was considered to be more representative.

Descriptive statistics for the physical infrastructure recoded into binary variables, along with the retained continuous variables are shown in Table 6 . The results presented are disaggregated into the two posted speed limits with the three survey periods (before, six months after, and two years after) combined. The mean and standard deviation of the speed varies across the two scenarios, but the same statistics for the physical characteristics remain broadly the same. The similarity of the sample size at each individual site is incorporated within the survey design and suggests no single site was overrepresented. Entries have been omitted where the variable is constant under certain circumstances. Each of the $60 \mathrm{mph}$ sites featured a junction, and there were no $70 \mathrm{mph}$ survey sites featuring a desirable minimum radius curve, street lighting, or a merge. The $2+1$ carriageway is only applicable to $60 \mathrm{mph}$ roads so does not feature as a variable in the $70 \mathrm{mph}$ model. The darkness indicator is only applicable to the 'all conditions' dataset, as it takes a constant 0 or 1 value in the light-only or dark-only models. 
Table 5. Speed survey site characteristics.

\begin{tabular}{|c|c|c|c|c|c|c|c|c|c|c|c|}
\hline \multirow{2}{*}{ Site } & \multirow{2}{*}{$\begin{array}{l}\text { PSL } \\
(\mathrm{mph})\end{array}$} & \multirow{2}{*}{$\begin{array}{c}\text { Carriageway } \\
\text { Type }\end{array}$} & \multirow{2}{*}{$\begin{array}{c}\text { Street } \\
\text { Lighting }\end{array}$} & \multirow{2}{*}{$\begin{array}{c}\text { Junction } \\
\text { Present }\end{array}$} & \multirow{2}{*}{$\begin{array}{l}\text { Merge } \\
\text { Present }\end{array}$} & \multicolumn{2}{|c|}{$\begin{array}{l}\text { Distance Since Last } \\
\text { Camera }(\mathrm{km})\end{array}$} & \multirow{2}{*}{$\begin{array}{c}\text { Treated } \\
\text { Approach } \\
\text { Length }(\mathbf{k m})\end{array}$} & \multirow{2}{*}{$\begin{array}{l}\text { Immediate } \\
\text { Approach } \\
\text { Gradient }\end{array}$} & \multirow{2}{*}{$\begin{array}{c}\text { Average } \\
\text { Half-Width } \\
\text { (m) }\end{array}$} & \multirow{2}{*}{$\begin{array}{c}\text { Curve } \\
\text { Radius } \\
\text { (m) }\end{array}$} \\
\hline & & & & & & $\begin{array}{l}\text { With } \\
\text { Flow }\end{array}$ & $\begin{array}{c}\text { Any } \\
\text { Direction }\end{array}$ & & & & \\
\hline 1 & 60 & Single & No & Yes & No & 1.062 & 1.062 & 0.329 & $-0.22 \%$ & 4.975 & 600 \\
\hline 2 & 60 & Single & No & Yes & No & 9.798 & 1.853 & 0.634 & $0.85 \%$ & 4.975 & 300 \\
\hline 3 & $60^{\mathrm{a}}$ & Single ${ }^{a}$ & Yes & Yes & No & 4.768 & 4.659 & 0.282 & $-0.95 \%$ & 6.525 & 1400 \\
\hline 4 & $60^{a}$ & Single ${ }^{a}$ & Yes & Yes & Yes & 6.424 & 4.200 & 2.403 & $0.95 \%$ & 6.975 & 600 \\
\hline 5 & 70 & Dual & No & No & No & 5.316 & 3.092 & 1.295 & $-1.00 \%$ & 8.3 & 700 \\
\hline 6 & 70 & Dual & No & Yes & No & 7.040 & 2.387 & 2.554 & $0.00 \%$ & 8.3 & 700 \\
\hline 7 & 70 & Dual & No & Yes & No & 4.101 & 1.877 & 0.080 & $0.00 \%$ & 8.8 & 1000 \\
\hline 8 & 60 & Single & No & Yes & No & 0.802 & 0.802 & 0.199 & $-0.63 \%$ & 5.75 & 1600 \\
\hline 9 & 60 & Single & No & Yes & No & 1.289 & 0.935 & 0.621 & $0.77 \%$ & 5.025 & 400 \\
\hline 10 & 60 & Single & No & Yes & No & 3.696 & 1.472 & 3.093 & $-0.26 \%$ & 4.4 & Tangent \\
\hline 11 & 60 & Single & No & Yes & No & 1.633 & 1.633 & 4.017 & $-0.51 \%$ & 4.4 & 1700 \\
\hline 12 & 60 & Single & No & Yes & No & 5.746 & 0.282 & 2.044 & $-3.07 \%$ & 5 & Tangent \\
\hline 13 & 60 & Single & No & Yes & No & 3.807 & 0.324 & 2.060 & $2.50 \%$ & 5.8 & Tangent \\
\hline 14 & 60 & Single & No & Yes & No & 6.352 & 0.324 & 2.650 & $-2.50 \%$ & 5.75 & Tangent \\
\hline 15 & 60 & $2+1$ & No & Yes & No & 3.261 & 0.870 & 1.514 & $-4.10 \%$ & 5.5 & 1700 \\
\hline 16 & 60 & $2+1$ & Yes & Yes & Yes & 7.591 & 1.563 & 3.889 & $0.90 \%$ & 5.55 & 300 \\
\hline 17 & 60 & Single & Yes & Yes & No & 1.993 & 1.993 & 0.246 & $-0.34 \%$ & 5.25 & 2000 \\
\hline 18 & 60 & Single & No & Yes & No & 10.048 & 0.111 & 0.412 & $-3.57 \%$ & 4.825 & 1200 \\
\hline 19 & 60 & Single & No & Yes & No & 0.111 & 0.111 & 0.114 & $3.65 \%$ & 5.225 & Tangent \\
\hline 20 & 70 & Dual & No & Yes & No & 11.719 & 0.137 & 0.896 & $3.50 \%$ & 7.3 & Tangent \\
\hline 21 & 70 & Dual & No & Yes & No & 5.675 & 5.675 & 0.184 & $2.00 \%$ & 7.3 & 800 \\
\hline
\end{tabular}

a Site featured central reserve but single running lanes-assigned as single carriageway with $60 \mathrm{mph}$ PSL. ${ }^{\mathrm{b}}$ Radii greater than $2880 \mathrm{~m}$ were assigned as tangents.

Table 6. Variable descriptive statistics.

\begin{tabular}{|c|c|c|c|c|}
\hline Variable Description & Mean & $\begin{array}{l}60 \mathrm{mph} \text { PSL } \\
\quad \begin{array}{l}n=6299 \\
\text { Standard Deviation }\end{array}\end{array}$ & Mean & $\begin{array}{l}70 \mathrm{mph} \text { PSL } \\
\quad n=2886 \\
\text { Standard Deviation }\end{array}$ \\
\hline 1. Measured speed (mph) & 53.93 & 6.795 & 62.11 & 9.064 \\
\hline 2. Darkness indicator ( 1 if dark; 0 otherwise) & 0.46 & 0.498 & 0.47 & 0.499 \\
\hline 3. Active Road Stud indicator ( 1 if present; 0 otherwise) & 0.65 & 0.477 & 0.62 & 0.486 \\
\hline 4. $2+1$ carriageway indicator ( 1 if present; 0 otherwise) & 0.14 & 0.350 & - & - \\
\hline 5. Street lighting indicator ( 1 if present; 0 otherwise) & 0.29 & 0.455 & - & - \\
\hline 6. Junction indicator ( 1 if present; 0 otherwise) & - & - & 0.79 & 0.408 \\
\hline 7. Merge indicator ( 1 if present; 0 otherwise) & 0.15 & 0.357 & - & - \\
\hline 8. Average approach gradient ( $\%$; up gradient +ve; down gradient - ve) & -0.384 & 2.010 & 0.966 & 1.653 \\
\hline 9. Average half-width (metres) & 5.419 & 0.681 & 7.949 & 0.591 \\
\hline 10. Desirable minimum curve indicator ( 1 if present; 0 otherwise) & 0.39 & 0.488 & - & - \\
\hline 11. One-step relaxation curve indicator ( 1 if present; 0 otherwise) & 0.14 & 0.350 & 0.38 & 0.487 \\
\hline 12. Two-step relaxation curve indicator ( 1 if present; 0 otherwise) & 0.18 & 0.384 & 0.41 & 0.491 \\
\hline 13. Distance since enforcement camera (with flow) $(\mathrm{km})$ & 4.274 & 3.029 & 6.873 & 2.644 \\
\hline 14. Distance since enforcement camera (any direction) (km) & 1.455 & 1.346 & 2.717 & 1.873 \\
\hline 15. Length of treated approach $(\mathrm{km})$ & 1.510 & 1.335 & 1.012 & 0.881 \\
\hline
\end{tabular}

\subsection{Correlation Analysis}

The Pearson's product-moment correlation coefficients between variables are shown in Tables 7 and 8 for the $60 \mathrm{mph}$ PSL and $70 \mathrm{mph}$ PSL datasets, respectively. In the $60 \mathrm{mph}$ dataset, small positive correlations between measured speed, the presence of a desirable minimum curve $(\mathrm{r}=0.11, n=6299, p<0.01)$, and the distance since the last enforcement camera in any direction $(\mathrm{r}=0.18, n=6299, p<0.01)$ were found. In the $70 \mathrm{mph}$ dataset, small positive correlations between measured speed, the presence of a two-step relaxation curve $(\mathrm{r}=0.16, n=2886, p<0.01)$, and the length of treated approach $(\mathrm{r}=0.18, n=2886$, $p<0.01$ ) were found. A small negative correlation was found between the measured speed and the presence of a two-step relaxation curve $(\mathrm{r}=-0.11, n=6299, p<0.01)$ in the $60 \mathrm{mph}$ dataset. In the $70 \mathrm{mph}$ dataset, a small negative correlation was found between measured speed and the presence of a one-step relaxation curve $(\mathrm{r}=-0.13, n=2886, p<0.01)$ 
Table 7. Correlation of measured speed with road factors (60 mph PSL).

\begin{tabular}{|c|c|c|c|c|c|c|c|c|c|c|c|c|c|c|c|}
\hline Variable & 1 & 2 & 3 & 4 & 5 & 6 & 7 & 8 & 9 & 10 & 11 & 12 & 13 & 14 & 15 \\
\hline 1 & - & & & & & & & & & & & & & & \\
\hline 2 & $0.05^{\mathrm{a}}$ & - & & & & & & & & & & & & & \\
\hline 3 & -0.01 & -0.02 & - & & & & & & & & & & & & \\
\hline 4 & 0.02 & 0.00 & $0.04^{\mathrm{a}}$ & - & & & & & & & & & & & \\
\hline 5 & $0.07^{\mathrm{a}}$ & 0.00 & -0.02 & 0.22 & - & & & & & & & & & & \\
\hline 6 & - & - & - & - & - & - & & & & & & & & & \\
\hline 7 & $0.08^{\mathrm{a}}$ & 0.00 & -0.02 & $0.44^{\mathrm{a}}$ & $0.65^{\mathrm{a}}$ & - & - & & & & & & & & \\
\hline 8 & $-0.09^{\mathrm{a}}$ & 0.00 & 0.00 & $-0.19^{\mathrm{a}}$ & $0.17^{\mathrm{a}}$ & - & $0.29^{\mathrm{a}}$ & - & & & & & & & \\
\hline 9 & $0.07^{\mathrm{a}}$ & -0.01 & $-0.07^{\mathrm{a}}$ & 0.06 & $0.61^{\mathrm{a}}$ & - & $0.51^{\mathrm{a}}$ & $0.14^{\mathrm{a}}$ & - & & & & & & \\
\hline 10 & $0.11^{\mathrm{a}}$ & 0.01 & 0.00 & $0.06^{\mathrm{a}}$ & $0.12^{\mathrm{a}}$ & - & $-0.34^{\mathrm{a}}$ & $-0.51^{a}$ & 0.00 & - & & & & & \\
\hline 11 & $0.09^{\mathrm{a}}$ & 0.00 & $-0.04^{\mathrm{a}}$ & $-0.17^{a}$ & $0.20^{\mathrm{a}}$ & - & $0.42^{\mathrm{a}}$ & $0.18^{a}$ & $0.35^{\mathrm{a}}$ & $-0.33^{\mathrm{a}}$ & - & & & & \\
\hline 12 & $-0.11^{\mathrm{a}}$ & 0.00 & $0.04^{\mathrm{a}}$ & $0.38^{a}$ & $0.14^{\mathrm{a}}$ & - & $0.36^{\mathrm{a}}$ & $0.32^{\mathrm{a}}$ & $-0.13^{\mathrm{a}}$ & $-0.38^{\mathrm{a}}$ & $-0.19^{a}$ & - & & & \\
\hline 13 & $0.02^{b}$ & 0.00 & 0.00 & $0.18^{a}$ & $0.20^{\mathrm{a}}$ & - & $0.38^{\mathrm{a}}$ & $-0.28^{a}$ & $0.15^{\mathrm{a}}$ & $-0.14^{\mathrm{a}}$ & $-0.06^{a}$ & $0.33^{a}$ & - & & \\
\hline 14 & $0.18^{\mathrm{a}}$ & 0.02 & $-0.05^{\mathrm{a}}$ & $-0.07^{a}$ & $0.77^{\mathrm{a}}$ & - & $0.44^{\mathrm{a}}$ & $0.13^{\mathrm{a}}$ & $0.64^{\mathrm{a}}$ & $0.15^{\mathrm{a}}$ & $0.37^{\mathrm{a}}$ & 0.01 & $0.14^{\mathrm{a}}$ & - & \\
\hline 15 & $0.07^{\mathrm{a}}$ & 0.01 & 0.02 & $0.39^{\mathrm{a}}$ & $0.12^{\mathrm{a}}$ & - & $0.52^{\mathrm{a}}$ & -0.01 & $-0.05^{\mathrm{a}}$ & $-0.31^{\mathrm{a}}$ & $-0.04^{\mathrm{a}}$ & $0.18^{a}$ & $0.27^{a}$ & $0.04^{\mathrm{a}}$ & - \\
\hline
\end{tabular}

$n=6299 ;-$ variable constant for all surveyed sites; ${ }^{a} 0.99$ level of confidence; ${ }^{\mathrm{b}} 0.95$ level of confidence.

Table 8. Correlation of measured speed with road factors (70 mph PSL).

\begin{tabular}{|c|c|c|c|c|c|c|c|c|c|c|c|c|c|c|c|}
\hline Variable & 1 & 2 & 3 & 4 & 5 & 6 & 7 & 8 & 9 & 10 & 11 & 12 & 13 & 14 & 15 \\
\hline 1 & - & & & & & & & & & & & & & & \\
\hline 2 & $0.05^{\mathrm{a}}$ & - & & & & & & & & & & & & & \\
\hline 3 & $-0.05^{\mathrm{a}}$ & $0.04^{\mathrm{a}}$ & - & & & & & & & & & & & & \\
\hline 4 & - & - & - & - & & & & & & & & & & & \\
\hline 5 & - & - & - & - & - & & & & & & & & & & \\
\hline 6 & -0.03 & 0.00 & 0.02 & - & - & - & & & & & & & & & \\
\hline 7 & - & - & - & - & - & - & - & & & & & & & & \\
\hline 8 & $-0.09^{\mathrm{a}}$ & $0.04^{\mathrm{b}}$ & 0.03 & - & - & $0.62^{\mathrm{a}}$ & - & - & & & & & & & \\
\hline 9 & $0.08^{a}$ & $-0.05^{a}$ & -0.02 & - & - & $-0.31^{\mathrm{a}}$ & - & $-0.86^{a}$ & - & & & & & & \\
\hline 10 & - & - & - & - & - & - & - & - & - & - & & & & & \\
\hline 11 & $-0.13^{a}$ & $0.04^{\mathrm{b}}$ & 0.02 & - & - & $0.41^{\mathrm{a}}$ & - & $0.09^{a}$ & $-0.03^{a}$ & - & - & & & & \\
\hline 12 & $0.16^{\mathrm{a}}$ & $-0.05^{a}$ & $-0.04^{b}$ & - & - & $-0.63^{a}$ & - & $-0.74^{a}$ & 0.49 & - & $-0.65^{a}$ & - & & & \\
\hline 13 & 0.02 & 0.00 & 0.01 & - & - & $0.31^{\mathrm{a}}$ & - & $0.76^{\mathrm{a}}$ & $-0.62^{a}$ & - & $-0.56^{\mathrm{a}}$ & $-0.23^{a}$ & - & & \\
\hline 14 & $-0.06^{\mathrm{a}}$ & $0.03^{b}$ & 0.00 & - & - & $-0.10^{a}$ & - & $-0.21^{\mathrm{a}}$ & $-0.17^{\mathrm{a}}$ & - & $0.58^{a}$ & 0.02 & $-0.64^{a}$ & - & \\
\hline 15 & $0.18^{a}$ & $-0.07^{a}$ & -0.03 & - & - & $-0.17^{a}$ & - & $-0.35^{a}$ & $0.26^{\mathrm{a}}$ & - & $-0.78^{a}$ & $0.83^{a}$ & $0.21^{\mathrm{a}}$ & $-0.26^{a}$ & - \\
\hline
\end{tabular}

$n=2886$; - variable constant for all surveyed sites; ${ }^{\mathrm{a}} 0.99$ level of confidence; ${ }^{\mathrm{b}} 0.95$ level of confidence.

In terms of the other variable pairs, in the $60 \mathrm{mph}$ PSL dataset, only one pair was found with $r>0.7$. In the $70 \mathrm{mph}$ PSL data set, four variable pairs were found with $r>0.7$. On this basis, there was little evidence of multi-collinearity; hence, the full variable datasets were taken forward for further linear regression analysis.

\subsection{Linear Regression Analysis}

The linear regression models are shown in Table 9 for the $60 \mathrm{mph}$ PSL and the $70 \mathrm{mph}$ PSL datasets. In the $60 \mathrm{mph}$ PSL model, the largest positive increase in speed was found to be associated with the presence of merges, with a $9.3 \mathrm{mph}$ increase suggested. Other variables contributing to increased speeds included the presence of darkness, the presence of $2+1$ carriageway, and the increasing distance from the last enforcement camera. Decreased speeds in the model were associated with the presence of street lighting, uphill gradients, and the presence of curves with radii smaller than the desirable minima. No dual carriageway sites featuring street lighting, a merge, or a curve of desirable minimum radius were part of the installations monitored. The statistically significant explanatory variables are therefore fewer in the $70 \mathrm{mph}$ PSL model. The presence of darkness and the increasing half-width were associated with increases in speed. In terms of the active road studs, their specific presence was found to reduce speeds, whereas increases in the length of installation were found to increase speeds. 
Table 9. Linear Regression Model.

\begin{tabular}{|c|c|c|}
\hline \multirow[b]{2}{*}{ Variable Description } & \multicolumn{2}{|c|}{ Regression Coefficients } \\
\hline & $\begin{array}{c}60 \mathrm{mph} \text { PSL } \\
n=6299\end{array}$ & $\begin{array}{c}70 \mathrm{mph} \text { PSL } \\
n=2886\end{array}$ \\
\hline 1. Constant & $65.089^{\mathrm{a}}$ & $55.348^{\mathrm{a}}$ \\
\hline 2. Darkness indicator ( 1 if dark; 0 otherwise) & $0.593^{\mathrm{a}}$ & $1.238^{\mathrm{a}}$ \\
\hline 3. Active Road Stud indicator ( 1 if present; 0 otherwise) & - & $-0.877^{b}$ \\
\hline 4. $2+1$ carriageway indicator ( 1 if present; 0 otherwise) & $0.982^{\mathrm{a}}$ & - \\
\hline 5. Street lighting indicator ( 1 if present; 0 otherwise) & $-6.166^{\mathrm{a}}$ & - \\
\hline 6. Junction indicator ( 1 if present; 0 otherwise) & - & - \\
\hline 7. Merge indicator ( 1 if present; 0 otherwise) & $9.320^{\mathrm{a}}$ & - \\
\hline 8. Average approach gradient ( $\%$; up gradient $+v e ;$ down gradient - ve) & $-0.285^{\mathrm{a}}$ & - \\
\hline 9. Average half-width (metres) & $-2.277^{a}$ & $0.614^{\mathrm{b}}$ \\
\hline 10. Desirable minimum curve indicator ( 1 if present; 0 otherwise) & - & - \\
\hline 11. One-step relaxation curve indicator ( 1 if present; 0 otherwise) & $-3.455^{\mathrm{a}}$ & - \\
\hline 12. Two-step relaxation curve indicator ( 1 if present; 0 otherwise) & $-4.352^{\mathrm{a}}$ & - \\
\hline 13. Distance since enforcement camera (with flow) $(\mathrm{km})$ & $-0.103^{b}$ & - \\
\hline 14. Distance since enforcement camera (any direction) (km) & $2.640^{\mathrm{a}}$ & - \\
\hline 15. Length of treated approach $(\mathrm{km})$ & $-0.703^{a}$ & $1.819^{\mathrm{a}}$ \\
\hline
\end{tabular}

— statistically insignificant variable (not included for estimation in model specification); ${ }^{\mathrm{a}} 0.99$ level of confidence; ${ }^{\mathrm{b}} 0.95$ level of confidence.

\section{Discussion}

Although the causal relationship between speed and the probability of a crash remains subject to debate, greater severities of injury can be expected at higher speeds [4]. As a result, practical interventions which may result in increases in speed should be viewed with a degree of concern. Even measures which are intended to improve the safety of the drivervehicle-road system may result in undesirable risk compensation by drivers and have a net opposite effect. For example, this phenomenon has been associated with interventions such as seat belts, anti-lock brakes, and the implementation of street lighting [29-31]. In the specific case of solar-powered road studs, if increases in driver confidence [17] were to translate to a corresponding increase in mean speed, this could result in increased crash rates [9-14]. The relationship between active road studs, other road features, and speed is therefore of considerable interest.

This research found that in the $60 \mathrm{mph}$ PSL sections when the route was taken as a whole, only very negligible reductions in mean speed were recorded, none of which approached significance. Essentially, from this it would appear that mean speed appears to be unaffected by a change from passive to active road studs on such roads, a result which reflects that found in the previously described simulator study [18]. No simulator study has looked at a $70 \mathrm{mph}$ dual carriageway route, and hence, the results found in this respect are believed to be new. In this case, a statistically significant reduction in mean speed of $1.5 \mathrm{mph}$ was found during the hours of darkness six months after the treatment. Some reduction in this figure occurred after two years, and it was no longer significant at the chosen alpha of 0.05 (although notably it still was at $\alpha=0.10$ ). Decreases in variance suggest that speeds become slightly more homogeneous, and large fluctuations are less evident, which is a positive outcome when the safety effects of speed differentials are considered $[5,6]$.

In terms of speeding drivers, the improved visibility from active road studs does not appear to change the mean excess speed in either the $60 \mathrm{mph}$ or $70 \mathrm{mph}$ PSL sections. Other research has suggested that reflective delineation helps drivers' speed awareness at night [32]. Given the additional information provided by the active studs, it seems probable that speeding drivers are doing so consciously with full knowledge of their actual speed. Whilst addressing speeding drivers may be an emotive issue with members of the public, failure to do so does not necessarily mean that safety benefits will not be achieved. Although, as discussed previously, the link between speed and individual crashes is a matter of debate, the link between mean speed and crash rate seems much clearer [8]. For 
example, application of the power model [11] would suggest the reduction in mean speed during darkness measured here could reduce the number of fatal crashes by up to $10 \%$.

Whilst significant global mean speed changes were restricted only to the $70 \mathrm{mph}$ PSL sections of the route, mean speed changes at selected individual sites across both speed limits were found. No site could realistically be considered the same; each had its own geometric and topographic characteristics. In many cases, the implications of such characteristics are intuitive. For example, it would be reasonable to expect drivers to traverse curves of one- and two-step design relaxations at a slower speed in general than those of a desirable minimum radius, if only in the interests of occupant comfort. On this basis, it would appear that any relationship between mean speed and road features is a complex one, where the active road stud may be a contributory variable in certain circumstances. The subsequent regression analysis undertaken provides some insight into how the active road stud, along with other variables, may be associated with mean speed.

In the $60 \mathrm{mph}$ PSL regression model, the greatest effect on speed was the presence of a merge. This could be a result of drivers travelling faster than usual to complete passing manoeuvres before the end of overtaking lanes. Whilst this result was statistically significant, it is noted that only two merge sites existed in the dataset, one of which was on a single carriageway divided by a central reserve, which is a relatively unusual arrangement. On this basis, it is suggested that other factors may contribute to this increase. Variables contributing to reductions in speed, particularly those related to gradients and curves, would seem intuitive; it seems quite possible that the speed of the vehicles may be affected by increased engine strain on the gradients and the discomfort and lower visibility experienced on the sharper curves. Where street lighting is not present, the increase in speed in the hours of darkness found in this study is consistent with other research findings $[29,33]$.

In terms of the active road studs, the presence of the studs was found to be insignificant in the $60 \mathrm{mph}$ PSL model. However, the length of a treated approach variable was retained. The decrease in mean speed associated with an increased length of stud treatment is a potentially interesting finding. However, it is noteworthy that the studs were installed only on the approaches to junctions, with the length of installation being proportionate to the importance of the junction itself. On this basis, it could be that drivers may, at least partially, have already adjusted their speed in anticipation of the conditions ahead, and the association with stud treatment length was merely coincident. Given that all the $60 \mathrm{mph}$ PSL sites were at junctions, unfortunately it was not possible to control for this possible effect with the data gathered.

In the $70 \mathrm{mph}$ PSL model, again the presence of darkness was associated with higher speeds, more so in fact than the former. Significantly, the presence of the active road stud appeared to influence speed, with a reduction of 1 to $1.5 \mathrm{mph}$ being implied. In the case of the length of the stud installation, the opposite to the $60 \mathrm{mph}$ PSL model occurs; in this scenario, speeds increase as the length of treated approach increases. It is known that the dual carriageway sections of this road are mostly used to provide overtaking opportunities. On this basis, it may be that longer sections of dual carriageway are more attractive for overtaking and therefore result in higher speeds, which could explain this apparent pattern.

The other variable of significance in the $70 \mathrm{mph}$ PSL model was road half-width. In this case, increases in half-width appeared to result in increased speeds. It has been suggested that the additional steering workload, along with a better perception of speed, is associated with slower speeds in narrower lane widths [34,35]. Such association could be expected during hours of daylight but less so during hours of darkness, where a driver's field of view and depth of field are restricted by the capability of the vehicle headlights. It could be that the presence of active road studs might enhance a driver's awareness and perception of speed, leading to this association.

Some limitations in the present work are acknowledged. Most of the survey sites were located on the approach to junctions as they were the focus of the original installation. It could be that drivers already moderate their speed when in such circumstances, in which 
case any change in mean speed may be suppressed. The work here was also entirely random in its sampling, and specific vehicle types were not recorded. Whilst this means the results are likely to be valid for typical traffic composition, the effects may be different between vehicle categories. This study also controlled for weather, with all the results obtained during benign conditions. One aspect in which active road studs are thought to be of particular benefit is during times of poor visibility. On this basis, their effect on mean speeds under such conditions could be worthy of further investigation.

\section{Conclusions}

The aim of this research was to measure the choice of speed by drivers, using realworld rural junctions and links and to determine whether changes in the speed of vehicles may be associated with the installation of active road studs. The null hypothesis stated that drivers do not change their speed in the presence of active road studs, and there is no difference in mean speeds before and after installation. Based on these findings, looking at the entire route, a universal rejection of the null hypothesis across all tests is not possible; there is no consistent correlation between mean speed and the presence of the active road studs at all sites. However, there appears to be some specific situations in which the null hypothesis could be rejected. Most notably, on the $70 \mathrm{mph}$ PSL dual carriageway sections, the presence of studs may contribute to mean speed reduction as part of a wider group of variables.

The results of this work are likely to be of interest to road safety engineers, specifically as the improved visibility resulting from the installation of active road studs appears unlikely to result in any corresponding increase in the mean speed of vehicles. This is a positive finding, as it means that any other safety benefits found, such as improved driver confidence or better lane discipline, would not be offset by the risk of greater crash severity through increased speed. On higher-speed dual carriageway sections, the presence of the stud may even result in a reduction in mean vehicle speeds. In road safety terms, this could mean that the severity of crashes may be decreased in the presence of the stud. This would appear to be a particularly positive outcome, given that these are the highest speed sections-and therefore potentially the highest crash severity-on the road network.

Author Contributions: Conceptualization, R.L. and J.C.; methodology, R.L.; software, R.L.; validation, J.C. and G.F.; formal analysis, R.L.; investigation, R.L.; resources, R.L.; data curation, R.L.; writing-original draft preparation, R.L.; writing-review and editing, R.L., J.C. and G.F.; visualization, R.L.; supervision, J.C. and G.F.; project administration, R.L. All authors have read and agreed to the published version of the manuscript.

Funding: This research received no external funding.

Data Availability Statement: Not applicable.

Acknowledgments: The authors would like to thank Amey for facilitating the inspection of the installation of the works during construction and Transport Scotland for the provision of the background information regarding the scheme.

Conflicts of Interest: The authors declare no conflict of interest.

\section{References}

1. World Health Organisation Global Status Report on Road Safety 2018; World Health Organisation: Geneva, Switzerland, 2018.

2. International Transport Forum towards Zero: Ambitious Road Safety Targets and the Safe System Approach; OECD: Paris, France, 2008; ISBN 9789282101957.

3. PIARC-World Road Association Road Safety Manual; PIARC (World Road Association): Paris, France, 2019.

4. Joksch, H.C. Velocity Change and Fatality Risk in a Crash-A Rule of Thumb. Accid. Anal. Prev. 1993, 25, 103-104. [CrossRef]

5. Cirillo, J.A. Interstate System Accident Research Study II, Interim Report II. Public Roads 1968, 35, 71-75.

6. Solomon, D.H. Accidents on Main Rural Highways: Related to Speed, Driver, and Vehicle; US Department of Transportation, Federal Highway Administration: Washington, DC, USA, 1964.

7. Taylor, M.C.; Lynam, D.A.; Baruya, A. The Effects of Drivers' Speed on the Frequency of Road Accidents; Transport Research Laboratory: Crowthorne, UK, 2000. 
8. Hauer, E. Speed and Safety. Transp. Res. Rec. 2009, 2103, 10-17. [CrossRef]

9. Elvik, R.; Christensen, P.; Helene Amundsen, A. Speed and Road Accidents an Evaluation of the Power Model; Transportøkonomisk Institutt: Oslo, Norway, 2004.

10. Finch, D.J.; Kompfner, P.; Lockwood, C.R.; Maycock, G. Speed, Speed Limits and Accidents; Transport Research Laboratory: Wokingham, UK, 1994.

11. Nilsson, G. Traffic Safety Dimensions and the Power Model to Describe the Effect of Speed on Safety. Ph.D. Thesis, Lund University, Lund, Sweden, 2004.

12. Nilsson, G. The Effects of Speed Limits on Traffic Crashes in Sweden. In Proceedings of the International Symposium on the Effects of Speed Limits on Traffic Crashes and Fuel Consumption; Organisation for Economy, Co-Operation, and Development (OECD), Dublin, Ireland, 6-8 October 1981.

13. Pantangi, S.S.; Fountas, G.; Anastasopoulos, P.C.; Pierowicz, J.; Majka, K.; Blatt, A. Do High Visibility Enforcement Programs Affect Aggressive Driving Behavior? An Empirical Analysis Using Naturalistic Driving Study Data. Accid. Anal. Prev. 2020, 138, 105361. [CrossRef] [PubMed]

14. Pantangi, S.S.; Ahmed, S.S.; Fountas, G.; Majka, K.; Anastasopoulos, P.C. Do High Visibility Crosswalks Improve Pedestrian Safety? A Correlated Grouped Random Parameters Approach Using Naturalistic Driving Study Data. Anal. Methods Accid. Res. 2021, 30, 100155. [CrossRef]

15. Boys, J.T.; Green, A.W. Intelligent Road-Studs-Lighting the Paths of the Future. Trans. Inst. Prof. Eng. N. Z. Gen. Sect. 1997, 24, 33-40.

16. Shahar, A.; Brémond, R. Toward Smart Active Road Studs for Lane Delineation. In Proceedings of the Transport Research Arena (TRA) 5th Conference: Transport Solutions from Research to Deployment, Paris, France, 14-17 April 2014.

17. Llewellyn, R.; Cowie, J.; Maher, M. Active Road Studs as an Alternative to Lighting on Rural Roads: Driver Safety Perception. Sustainability 2020, 12, 9648. [CrossRef]

18. Reed, N. PPR143 Driver Behaviour in Response to Actively Illuminated Road Studs: A Simulator Study; Transport Research Laboratory: Crowthorne, UK, 2006.

19. Shahar, A.; Bremond, R.; Villa, C. Can Light Emitting Diode-Based Road Studs Improve Vehicle Control in Curves at Night? A Driving Simulator Study. Lighting Res. Technol. 2018, 50, 266-281. [CrossRef]

20. Styles, T.; Cairney, P.; Studwick, G.; Purtill, S. Effects of Self-Activated Pavement Markers on Driver Behaviour. Road Transp. Res. 2004, 13, 98-100.

21. Styles, T.; Cairney, P.; Studwick, G.; Purtill, S. Trial and Evaluation of Internally Illuminated Pavement Markers. In Proceedings of the Road Safety Research, Policing and Education Conference, Sydney, Australia, 24-26 September 2003; Volume 2, pp. 550-555.

22. Voigt, A.P.; Carson, J.L.; Tydlacka, J.; Gray, L.S. Applications of Illuminated, Active, In-Pavement Marker Systems; Transportation Research Board: Washington, DC, USA, 2008; ISBN 978-0-309-27955-0.

23. Rutherford, N. More than 6000 Caught Speeding on A1 through Borders. Available online: https://www.bbc.co.uk/news/ukscotland-south-scotland-33568848 (accessed on 8 February 2021).

24. Scottish Borders Council Minutes of the Berwickshire Area Forum-3 September 2015. Available online: https://scottishborders. moderngov.co.uk/ieListDocuments.aspx?CId=183\&MID=252\#AI2933 (accessed on 17 April 2020).

25. Ki, Y.K.; Baik, D.K. Model for Accurate Speed Measurement Using Double-Loop Detectors. IEEE Trans. Veh. Technol. 2006, 55, 1094-1101. [CrossRef]

26. Taghvaeeyan, S.; Rajamani, R. Portable Roadside Sensors for Vehicle Counting, Classification, and Speed Measurement. IEEE Trans. Intell. Transp. Syst. 2014, 15, 73-83. [CrossRef]

27. Design Manual for Roads and Bridges, CD 109 Revision 1: Highway Link Design. Available online: https://www. standardsforhighways.co.uk/prod/attachments/c27c55b7-2dfc-4597-923a-4d1b4bd6c9fa (accessed on 10 February 2021).

28. Washington, S.; Karlaftis, M.; Mannering, F.; Anastasopoulos, P. Statistical and Econometric Methods for Transportation Data Analysis; Chapman and Hall/CRC: New York, NY, USA, 2020; ISBN 0429244010.

29. Assum, T.; Bjørnskau, T.; Fosser, S.; Sagberg, F. Risk Compensation-the Case of Road Lighting. Accid. Anal. Prev. 1999, 31, 545-553. [CrossRef]

30. Fountas, G.; Fonzone, A.; Gharavi, N.; Rye, T. The Joint Effect of Weather and Lighting Conditions on Injury Severities of Single-Vehicle Accidents. Anal. Methods Accid. Res. 2020, 27, 100124. [CrossRef]

31. Winston, C.; Maheshri, V.; Mannering, F. An Exploration of the Offset Hypothesis Using Disaggregate Data: The Case of Airbags and Antilock Brakes. J. Risk Uncertain. 2006, 32, 83-99. [CrossRef]

32. Triggs, T.J.; Berenyi, J.S. Estimation of Automobile Speed under Day and Night Conditions. Hum. Factors J. Hum. Factors Ergon. Soc. 1982, 24, 111-114. [CrossRef] [PubMed]

33. Jägerbrand, A.K.; Sjöbergh, J.; Martins, M.; Pereira, N.; Reis, R.; Tomaz, E.; Jägerbrand, A.K.; Sjöbergh, J. Effects of Weather Conditions, Light Conditions, and Road Lighting on Vehicle Speed. SpringerPlus 2016, 5, 505. [CrossRef] [PubMed]

34. WAARD, D.D.; Jessurun, M.; Steyvers, F.J.; Reggatt, P.T.; Brookhuis, K.A. Effect of Road Layout and Road Environment on Driving Performance, Drivers' Physiology and Road Appreciation. Ergonomics 1995, 38, 1395-1407. [CrossRef] [PubMed]

35. Godley, S.T.; Triggs, T.J.; Fildes, B.N. Perceptual Lane Width, Wide Perceptual Road Centre Markings and Driving Speeds. Ergonomics 2004, 47, 237-256. [CrossRef] [PubMed] 